\title{
ARTICLE
}

Molecular Diagnostics

\section{Retrospective observational study of HER2 immunohistochemistry in borderline breast cancer patients undergoing neoadjuvant therapy, with an emphasis on Group 2 (HER2/CEP17 ratio $\geq 2.0, H E R 2$ copy number $<4.0$ signals/cell) cases}

\author{
Emad A. Rakha (D) ${ }^{1,2,3}$, Islam M. Miligy ${ }^{2,3}$, Cecily M. Quinn ${ }^{4}$, Elena Provenzano ${ }^{5}$, Abeer M. Shaaban (1D ${ }^{6}$, Caterina Marchiò ${ }^{7,8}$, \\ Michael S. Toss ${ }^{2}$, Grace Gallagy ${ }^{9}$, Ciara Murray ${ }^{4}$, Janice Walshe ${ }^{4}$, Ayaka Katayama ${ }^{2}$, Karim Eldib ${ }^{1}$, Nahla Badr ${ }^{6}$, Bruce Tanchel ${ }^{6}$, \\ Rebecca Millican-Slater ${ }^{10}$, Colin Purdie ${ }^{11}$, Dave Purnell ${ }^{12}$, Sarah E. Pinder (D) $^{13}$, Ian O. Ellis (iD $^{1,2}$ and Andrew H. S. Lee ${ }^{1}$
}

BACKGROUND: The ASCO/CAP guidance on HER2 testing in breast cancer (BC) has recently changed. Group 2 tumours with immunohistochemistry score $2+$ and HER2/CEP17 ratio $\geq 2.0$ and HER2 copy number $<4.0$ signals/cell were re-classified as HER2 negative. This study aims to examine the response of Group 2 tumours to neoadjuvant chemotherapy (NACT).

METHODS: 749 BC cases were identified from 11 institutions. The association between HER2 groups and pathological complete response $(\mathrm{pCR})$ was assessed.

RESULTS: $54 \%$ of immunohistochemistry HER2 positive (score 3+) BCs showed pCR, compared to $19 \%$ of immunohistochemistry 2+ FISH amplified cases. $27 \%$ of Group 2 treated with HER2 targeted therapy achieved pCR, compared to 19 and $11 \%$ in the combined Groups $1+3$ and Groups $4+5$, respectively. No difference in pCR rates was identified between Group 2 and Group 1 or combined Groups $1+3$. However, Group 2 response rate was higher than Groups $4+5(p=0.017)$.

CONCLUSION: No difference in PCR was detected in tumours with a HER2/CEP17 ratio $\geq 2.0$ and a HER2 score $2+$ by IHC when stratified by HER2 gene copy number. Our data suggest that ASCO/CAP HER2 Group 2 carcinomas should be evaluated further with respect to eligibility for HER2 targeted therapy.

British Journal of Cancer (2021) 124:1836-1842; https://doi.org/10.1038/s41416-021-01351-8

\section{BACKGROUND}

Approximately $15-20 \%$ of newly diagnosed invasive breast cancers (BC) show human epidermal growth factor receptor 2 (HER2) protein overexpression, usually due to HER2 gene amplification. ${ }^{1-4}$ HER2 overexpression is associated with a worse prognosis in patients who do not receive adjuvant systemic therapy and is predictive of response to several systemic therapies, ${ }^{5}$ in particular to HER2 targeted treatments. ${ }^{6-9}$ Hence, eligibility criteria based on HER2 status have been developed to optimise patient selection for these expensive and potentially toxic targeted agents and have evolved over time. ${ }^{3,4,10}$
The early trials of trastuzumab in metastatic BC enrolled patients with HER2 status defined using immunohistochemistry (IHC) assays alone and considered both $3+$ and $2+$ IHC scores as eligible for these trials. ${ }^{4,6,7,11}$ Subsequent analyses identified that only patients with HER2 positive BC, defined as IHC 3+ reactivity and/or HER2 gene amplification confirmed by fluorescent in situ hybridisation (FISH), benefit from HER2 targeted therapies. ${ }^{6,7,12-14}$ The Food and Drug Administration (FDA) definition of HER2 positivity was updated to IHC $3+$ or $2+$ with HER2 gene amplification (defined as HER2/ chromosome enumeration probe 17 [CEP17] ratio $\geq 2.0$, regardless of the HER2 copy number). ${ }^{13,15,16}$ This definition was endorsed by the

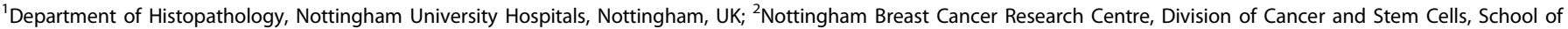

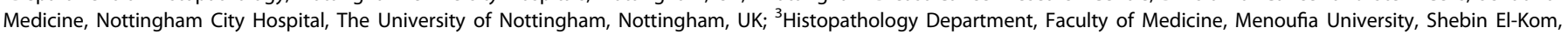

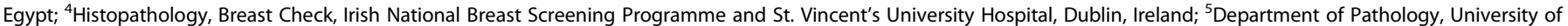

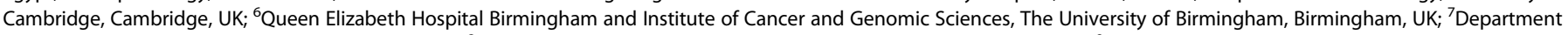
of Medical Sciences, University of Turin, Turin, Italy; ${ }^{8}$ Pathology Unit, Candiolo Cancer Institute, FPO-IRCCS, Candiolo, Italy; ${ }^{9}$ Discipline of Pathology, School of Medicine, Lambe

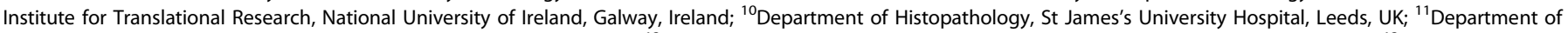

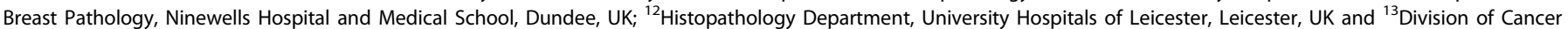
Studies, King's College London, Guy's Hospital, London, UK Correspondence: Emad A. Rakha (emad.rakha@nottingham.ac.uk) 
Table 1. Summary of the cohort including the distribution of the different HER2 groups and other variables.

\begin{tabular}{|c|c|c|c|c|c|c|c|c|}
\hline \multirow[t]{2}{*}{ Variables } & \multicolumn{7}{|c|}{ HER2 IHC defined Groups } & \multirow{2}{*}{$\begin{array}{l}\text { Total } \\
\text { No. (\%) }\end{array}$} \\
\hline & $\begin{array}{l}\text { Group } 1 \\
\text { No. (\%) }\end{array}$ & $\begin{array}{l}\text { Group } 2 \\
\text { No. (\%) }\end{array}$ & $\begin{array}{l}\text { Group } 3 \\
\text { No. (\%) }\end{array}$ & $\begin{array}{l}\text { Group } 4 \\
\text { No. (\%) }\end{array}$ & $\begin{array}{l}\text { Group } 5 \\
\text { No. (\%) }\end{array}$ & $\begin{array}{l}\text { IHC 3+ Group } \\
\text { (positive control) } \\
\text { No. }(\%)\end{array}$ & $\begin{array}{l}\text { IHC 0/1+ Group } \\
\text { (negative control) } \\
\text { No. }(\%)\end{array}$ & \\
\hline Total number & $121(16)$ & $46(6)$ & $13(2)$ & $84(11)$ & $106(14)$ & $146(20)$ & $233(31)$ & 749 (100) \\
\hline \multicolumn{9}{|l|}{ Tumour grade } \\
\hline 2 & $63(54)$ & $25(56)$ & $5(38)$ & $39(47)$ & $69(66)$ & $83(61)$ & $130(56)$ & $414(56)$ \\
\hline 3 & $53(45)$ & $19(42)$ & $7(54)$ & $42(51)$ & $32(31)$ & $52(38)$ & $100(43)$ & $305(42)$ \\
\hline \multicolumn{9}{|l|}{ Oestrogen receptor } \\
\hline Negative & $26(21)$ & $12(26)$ & $0(0)$ & $16(19)$ & $26(25)$ & $64(44)$ & $113(49)$ & $257(35)$ \\
\hline Positive & $95(79)$ & $34(74)$ & $13(100)$ & $68(81)$ & $80(75)$ & $81(56)$ & $118(51)$ & $489(65)$ \\
\hline No response & $5(4)$ & $2(4)$ & $0(0)$ & $5(6)$ & $17(16)$ & $10(7)$ & $37(16)$ & $76(10)$ \\
\hline Partial response & $94(78)$ & $32(70)$ & $12(92)$ & $70(83)$ & $77(73)$ & $57(39)$ & $147(63)$ & $489(65)$ \\
\hline $\begin{array}{l}\text { Pathological complete } \\
\text { response }\end{array}$ & $22(18)$ & $12(26)$ & $1(8)$ & $9(11)$ & $12(11)$ & $79(54)$ & $49(21)$ & $184(25)$ \\
\hline $\begin{array}{l}\text { HER2 gene copy } \\
\text { number (Mean) }\end{array}$ & 7.40 & 3.40 & 6.92 & 4.63 & 2.56 & 12.57 & - & - \\
\hline Median (range) & $7.6(4.0-42.2)$ & $3.4(2.2-3.9)$ & $6.5(6.1-7.4)$ & $4.6(4.0-5.6)$ & $2.6(1.4-3.9)$ & $10.8(8.4-17.3)$ & - & - \\
\hline $\begin{array}{l}\text { CEP17 copy } \\
\text { number (mean) }\end{array}$ & 2.14 & 1.48 & 4.33 & 3.13 & 1.98 & 2.93 & - & - \\
\hline Median (range) & $2.1(1.2-5.7)$ & $1.5(1.0-1.9)$ & $4.1(3.2-5.5)$ & $3.3(2.2-4.9)$ & $2.0(1.2-12.3)$ & $2.9(2.6-3.5)$ & - & - \\
\hline
\end{tabular}

early HER2 guidelines in the United Kingdom (UK). ${ }^{17,18}$ Subsequent guidelines by the American Society of Clinical Oncology (ASCO)/ College of American Pathologists (CAP) in $2007^{10}$ and $2013^{4}$ and the further UK 2015 update $^{19}$ expanded the definition of positivity to include tumours with an average HER2 gene copy number $\geq 6$ signals/nucleus regardless of the HER2/CEP17 ratio.

In 2018, ASCO/CAP published an update to refine the definition of cases showing mismatch between the HER2/CEP17 ratio and HER2 gene copy number, comprising $\sim 4-15 \%$ of cases. ${ }^{3}$ Possible combinations of the ratio and gene copy number were classified into 5 groups (Table 1). Unlike Group 1 and Group 3, Group 2, defined as a HER2/CEP17 ratio $\geq 2.0$ with an average HER2 copy number $<4.0$ signals per cell with $\mathrm{IHC}$ score of $2+$, was re-classified from HER2 positive ${ }^{4,19}$ to HER2 negative. ${ }^{3}$ This change was based on the lack of substantive evidence for the efficacy of HER2targeted therapy in such tumours in terms of survival benefit. ${ }^{3,20}$ These tumours are rare. In a study of 4331 tumours with known HER2/CEP17 ratio, HER2 copy number and HER2 IHC status, Press et al. ${ }^{20}$ identified only 35 Group 2 tumours, of which only three displayed an IHC 2+ score. Similar findings were observed by Ballard et al., who found $1.4 \%$ of tumours fell in this group they called 'monosomy non-classical' HER2 amplified BC cases (ratio $\geq$ 2.0 with an average $H E R 2$ copy number $<4.0$ signals per cell). ${ }^{21}$ The other two groups in their 'non classical amplification category' were designated as the 'co-amplified group' (ratio $<2.0$, and average HER2 copy number/cell $\geq 6.0$ ) and a 'low amplified group' (ratio $\geq 2.0$ and average HER2 copy number/cell 4.0-5.9) and represented $0.8 \%$ and $2.1 \%$ of cases, respectively. The limited number of patients with such tumours in the first generation of adjuvant trastuzumab trials has been an obstacle to drawing definitive conclusions regarding their response to HER2 targeted therapy, and clinical data for this unusual category of cases are desperately required.

In view of the low incidence of Group 2 tumours and the difficulty in identifying sufficient numbers to demonstrate a reliable survival benefit of targeted therapy, this study aimed to assess the behaviour of these tumours in the neoadjuvant setting as compared to the other well-defined groups, utilising a large multi-institutional cohort. Complete pathological response (pCR) to neoadjuvant therapy is a recognised surrogate for survival outcomes and, when compared to definite HER2 positive $(3+)$ and HER2 negative $(0 / 1+)$ groups, provides an indication of the underlying biology of these tumours with respect to the HER2 pathway activation and response to anti-HER2 therapy.

\section{METHODS}

Study cohort

We analysed a retrospective cohort of $1374 \mathrm{BC}$ patients who received neoadjuvant chemotherapy (NACT), with or without 
targeted therapy, and subsequent surgical resection in the years 2013-2019 from 11 institutions (Nottingham University Hospitals NHS Trust; Addenbrookes Hospital, Cambridge; University Hospitals Birmingham NHS Foundation Trust; University Hospitals of Leicester NHS Trust; St. Vincent's University Hospital, Dublin; University Hospital Galway; St. Helens and Knowsley Teaching Hospital NHS Trust, Liverpool; Guy's and St. Thomas' Hospital, London; Ninewells Hospital, Dundee, Leeds Teaching Hospitals NHS Trust, University of Turin, Italy). Inclusion criteria included availability of data on HER2 gene copy number and HER2/CEP17 ratio, NACT and pathological response details with emphasis on Group 2 tumours. As control groups, some cases with IHC scores of HER2 $3+$ and $0 / 1+$ were included (Table 1). Cases were identified and data collected from all centres based on these defined criteria to avoid sample bias.

Histological grade, details of oestrogen receptor (ER) status and treatment regimen received were also collected. pCR was defined as no residual invasive carcinoma in both the breast and axillary lymph nodes regardless of the presence of residual ductal carcinoma in situ (ypT0/is ypN0). ${ }^{23}$ All histopathological information was obtained from the original pathology reports. Anonymised data were analysed centrally. HER2 status was assessed using $\mathrm{IHC}$ and $\mathrm{ISH}$, as described in the UK guidelines, ${ }^{19}$ with primary IHC, followed by ISH on all borderline (2+) cases. In cases with an unusual ISH pattern, such as the target study cohort, the existing UK guidelines mandate counting 60 instead of 20 cells. According to the IHC and ISH results, the tumours were classified into the ASCO/CAP HER2 Groups ${ }^{3}$ (Table 1). ER positivity were defined as nuclear staining of $\geq 1 \%$ of invasive tumour cells. ${ }^{24}$

Patients were considered eligible for HER2 targeted therapies if their tumours showed a HER2 IHC score of $3+$, or 2+ with HER2/ CEP17 ratio $\geq 2.0$ regardless of the HER2 copy number (i.e. ASCO/ CAP Groups 1 and 2) or if the HER2 copy number was $\geq 6$ (Group 3 ). For subgroup analysis in this study, patients were categorised according to HER2 status into (1) Groups 1, 2 and 3, and (2) Groups 4 and 5. Patients were subdivided into two groups based on the type of neoadjuvant therapy received: (1) chemotherapy in combination with HER2 targeted therapy, trastuzumab alone or with either pertuzumab or lapatinib and (2) patients who received chemotherapy only. Chemotherapy regimens given were in accordance with individual unit protocols and included anthracycline and taxane, anthracycline without taxane or nonanthracycline based regimens.

This study was approved by the Nottingham Research Tissue Bank Access Committee under the IRAS Project ID: 184265. Data were collected as fully anonymised.

Statistical analysis

Statistical analysis was performed with SPSS (IBM SPSS Statistic, Version 24.0). Associations between clinicopathological variables and $\mathrm{pCR}$ were examined with Pearson Chi-square with Yates correction $\left(x^{2}\right)$ or Fisher's exact tests, as appropriate. Bonferroni correction for multiple testing was used to adjust $p$ values. Proportional odds logistic regression test was used to adjust cofounders whenever needed. A two-tailed $p$-value $<0.05$ was considered statistically significant.

\section{RESULTS}

Of the informative cases, 749 patients received NACT, with or without HER2 targeted therapy. This included 233 patients with negative HER2 status (IHC score 0 or $1+$ ), and 516 patients with a HER2 IHC score of $2+(n=370)$ or $3+(n=146)$ (Table 1). There was a strong correlation between positive HER2 status (IHC $3+$ and FISH-amplified Groups 1, 2 and 3) and response to NACT ( $p<$ $0.0001)$ and this correlation was maintained on stratifying based on ER status $(p=0.054$ and $p<0.0001$ in the ER negative and ER positive groups, respectively). BC patients with HER2 IHC score of 3 + achieved pCR in $54 \%$ of cases, compared to $19 \%$ of those with IHC score of $2+$ with FISH amplification (HER2/CEP17 ratio $\geq 2.0$ or $H E R 2$ gene copy number $\geq 6.0$ (combined Groups $1,2+3)(p<$ 0.0001 ) (Supplementary Table 1). The response to neoadjuvant therapy in group 2 was independent of other histological and treatment factors (Supplementary Table 2). This difference was significant in the subgroup of women with ER positive BC who received HER2 targeted therapy, here the IHC 3+ tumours showed a pCR rate of $58 \%$ compared to $15 \%$ in the IHC $2+$ FISH amplified Groups $(1,2$ and $3 ; 19 / 123)(p<0.0001)$, but not in the ER negative subgroup (pCR rate of $53 \%$ for IHC $3+$ versus $38 \%$ IHC $2+$ amplified, $(p=0.68)$ ) (Table 2). The magnitude of benefit from the addition of HER2 targeted therapy to chemotherapy was the same in both HER2 positive groups (IHC $3+$ and the IHC 2+ FISH amplified) with a 2.3-fold increase in the pCR rate $(24-56 \%$ and 9-21\%, respectively) (Supplementary Table 1).

The ASCO/CAP Group 2 patients $(n=46)$ showed pCR in $26 \%$ of tumours compared with $18 \%$ of those in Group 1 and $8 \%$ of those in Group 3, respectively (both currently categorised as HER2 positive in the UK) (Table 1). There was no significant difference in the response rate between Group 2 and Group $1(p=0.70)$ or between Group 2 and combined Groups $1+3(p=0.58)$. Similar results were identified when the cohorts were stratified according to HER2 targeted therapy or ER status; the response rate in Group 2 was not different to Group 1 tumours $(p=0.575$ and $p=0.375$ in the ER negative and ER positive cases, respectively) or combined Group 1 and Group 3 tumours $(p=0.73$ and $p=0.44$ in the ER negative and ER positive cases, respectively).

Group 2 tumours showed lower pCR rates compared to those in the HER2 IHC $3+$ group $(p=0.001)$. This difference was maintained in the ER positive tumours $(p<0.0001)$ but not in ER negative cases $(p=0.42)$. Although the response rate of Group 2 tumours was higher than that of the combined Groups 4 and 5 $(p=0.021)$, this difference was not evident when the cohort was stratified based on ER status $(p>0.05)$. The $\mathrm{pCR}$ in patients with HER2 negative tumours (IHC 0 or $1+$ ) receiving NACT was $21 \%$ (30\% in ER negative and $13 \%$ in ER positive) compared with $27 \%$ of patients in Group 2 receiving NACT and HER2 targeted treatment (37\% in ER negative and $20 \%$ in ER positive) (Table 2).

\section{DISCUSSION}

HER2 expression status is critical for selecting BC patients eligible for HER2 targeted therapies. Currently, IHC and FISH are regarded as equivalent assays for the assessment of HER2 status, due to their high concordance rate. Approximately $15-30 \%$ of BCs are IHC equivocal $(2+)$, of which $15-30 \%$ are HER2 amplified. IHC $2+$ amplified tumours comprise $\sim 20-40 \%$ of HER2 positive cases. $^{3,22,25,26}$

HER2 protein, and not the gene amplification per se, drives BC growth and progression, and is blocked using targeted agents. Emerging evidence indicates that $\mathrm{BC}$ patients with strong protein expression (IHC $3+$ ) benefit to a greater extent than those with gene amplification but with a borderline level of protein expression (IHC $2+$ amplified). ${ }^{27}$ IHC $3+$ cases almost always show high level gene amplification, whereas the IHC $2+$ cases often show low level amplification and/or heterogeneity. ${ }^{6,27-30}$ Response to NACT plus anti-HER2 targeted therapy occurs more frequently in tumours with HER2/CEP17 ratios $>3.7$ and HER2 gene copy number $>11.5 .{ }^{28}$ In a study of HER2-targeted therapy without chemotherapy, none of the 11 patients with HER2/CEP17 ratio $<4.0$ and/or HER2 gene copy number $<10.0$ achieved $\mathrm{pCR}$, compared to $29 \%$ of patients with ratios $>4$ and/or HER2 copy number $>10 .^{31}$ Although some studies failed to demonstrate an association between the degree of HER2 gene amplification and response to adjuvant HER2 targeted therapies, the number of events in these studies was low. ${ }^{20,29,32}$ 
Table 2. Degree of pathological response in subgroups based on HER2 targeted therapy and oestrogen receptor status.

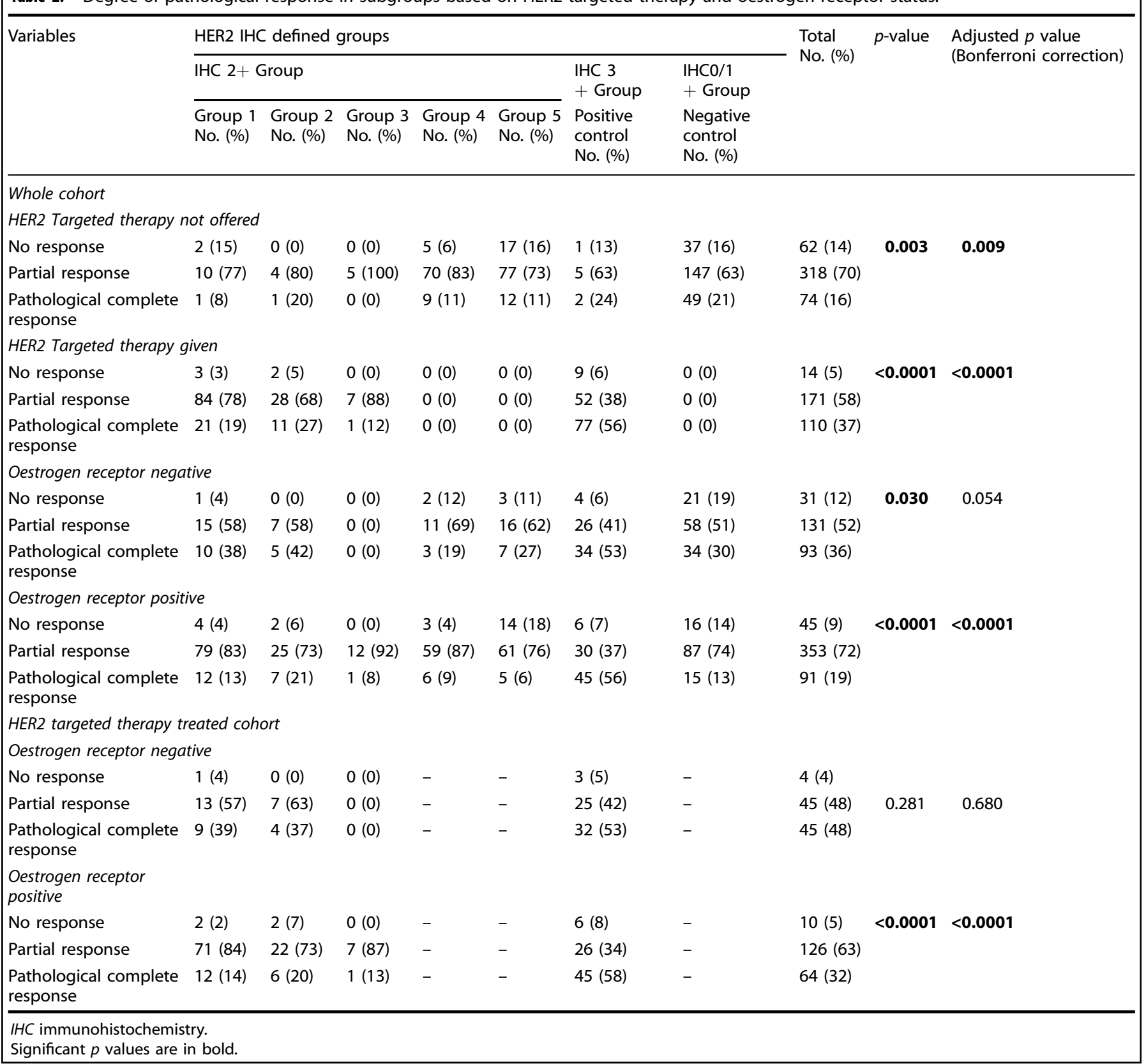

It is not surprising that BCs with bona fide HER2 positivity, as evidenced by protein overexpression (IHC 3+) and/or high-level gene amplification, are more dependent on HER2 to maintain their malignant phenotype and are more responsive to HER2 targeted therapy. This is also reflected in studies looking at gene expression analysis, with cancers belonging to the HER2-enriched intrinsic subtype showing higher $\mathrm{pCR}$ rates and the patients showing an improved event-free survival than those with nonHER2-enriched tumours. ${ }^{33}$ Supporting this, and in line with our results, Krystel-Whittemore et al. reported that $\mathrm{BC}$ with IHC $3+$ HER2 protein over-expression showed significantly higher $\mathrm{pCR}$ rate $(67 \%)$ compared to $\mathrm{BC}$ with $\mathrm{IHC} 2+$ and HER2 gene amplification (17\%). ${ }^{27}$

A variable level of response of HER2 positive BC to NACT (with the same therapeutic agents) has been reported, with $\mathrm{pCR}$ rates ranging from 23 to $70 \%$ in various studies. ${ }^{23,34,35}$ Although the NACT $p C R$ rate of the $I H C 2+B C s$ with evidence of HER2 amplification does not appear to differ from that of HER2 negative cases (IHC $0 / 1+$ ), which varies between 10 and $35 \%,{ }^{23,34,36}$ the magnitude of benefit from the addition of anti-HER2 targeted therapy is more important. Our results indicate that both groups (IHC 3+ and IHC 2+ FISH amplified) benefit from the addition of anti-HER2 targeted therapy despite the difference in the overall pCR rates achieved in each group. In clinical practice, categorisation of BC with equivocal protein expression (IHC 2+) but with HER2 gene amplification remains a challenge. Determination of the level, or pattern, of amplification associated with survival benefits from anti-HER2 therapies remains to be defined. There is an agreement that $\mathrm{BC}$ with $H E R 2$ gene copy number $\geq 6.0$ are categorised as HER2 positive and historically a ratio $\geq 2.0$ alone was used to define HER2 positivity regardless of the gene copy number. ${ }^{10,17,19}$ However, there are tumours with HER2/CEP17 ratio $\geq 2.0$ and HER2 copy number $<6.0$ and categorisation of these cases is difficult due to their rarity and consequent lack of 
evidence on treatment efficacy. The latest ASCO/CAP guidelines update published in 2018 re-classified these tumours into 2 groups: Group 1 (HER2/CEP17 ratio $\geq 2.0$ and HER2 copy number $>4.0$ ) remained as HER2 positive but Group 2 (ratio $\geq 2.0$ and $H E R 2$ gene copy number $<4.0$ ) was changed to HER2 negative.

Applying the 2018 guidelines has resulted in an increase in the proportion of HER2 negative cases compared with the 2013 classification. ${ }^{37-39}$ Evidence of pathological response in the neoadjuvant setting as a surrogate end point for survival outcome is a reasonable option, as we hypothesised in this study. Our results show that both groups have an inferior $\mathrm{pCR}$ compared to $\mathrm{IHC} 3+$ but have a similar pCR rate to each other, which is slightly higher than the $\mathrm{pCR}$ rate in HER2 negative cases receiving chemotherapy alone. In a recent study by Wang et al., ${ }^{40}$ there was no significant difference between Group $2(n=30)$ and Group 1 ( $n=100$ ) tumours regarding the outcome in terms of disease-free or overall survival in patients treated with or without targeted therapy. These results are consistent with our study, which did not find a difference in response rate to NACT and HER2 targeted treatment between Group 2 and Group 1 or between Group 2 and combined Groups 1 and 3. In the study of Perez et al. $(n=794)$, ${ }^{29}$ $1.5 \%$ of cases with a ratio $\geq 2.0$ were $\mathrm{IHC} 0 / 1+$ and $10 \%$ were $\mathrm{IHC} 2$ + whereas $88.5 \%$ were classified as $3+$ for HER2 IHC regardless of the HER2 gene copy number; this supports the earlier concept that cases with ratios $\geq 2.0$ are typically HER2 positive. In the adjuvant setting, Press et al. ${ }^{20}$ did not find a benefit from adjuvant trastuzumab therapy in patients with Group 2 tumours. However, $92 \%$ of Group 2 patients in the study were classified as IHC 0 or $1+$, which may explain the lack of benefit. In that study, the distribution of HER2 IHC score $(0 / 1+, 2+$ or $3+)$ in tumours with HER2 copy number $<4.0$ and those with $\geq 4.0-6.0$ was similar whereas the difference in the distribution was significantly different between ratios $<2$ and $\geq 2.0$ with $47 \%$ of cases with a ratio $\geq 2.0$ scored as $3+.{ }^{20}$ Although $50 \%$ of cases with HER2 copy number $\geq 6.0$ scored $3+$ this was observed only when the ratio was $\geq 2.0$ compared to $11 \%$ when the ratio was $<2.0$; further emphasising the impact of the HER2/CEP17 ratios on HER2 protein expression. $^{20}$

Our study confirms that in patients with HER2 positive BC who receive targeted therapy, ER status is important clinically. The best response is seen in IHC 3 + tumours regardless of ER status, likely reflecting the dominance of HER2 over the ER pathway. However, in patients with HER2 positive tumours that are IHC 2+ amplified, there is a significant impact of ER status on the response rate; $38 \%$ pCR rate in ER negative tumours compared to $15 \%$ in ER positive tumours, which may reflect the mixed effect of HER2 and ER pathway activation on BC growth and progression. ${ }^{41-43}$ When the analysis was limited to patients who had received chemotherapy and HER2 targeted therapy and the cohort was stratified based on ER expression, the response rate of Group 2 was not different to that of Group 1 tumours or of the combined Group 1 and Group 3 tumours. Interestingly, in the subgroup of patients with ER positive $B C$ who received chemotherapy and HER2 targeted therapy, those tumours that were IHC 3 + showed the highest $\mathrm{pCR}$ rate $(58 \%)$ compared to $14 \%$ in the IHC $2+/$ ISH amplified tumours (Groups 1 and 3) (or 15\% if Group 2 was included; combined Groups 1, 2 and $3)$. In the $E R$ negative subgroup of $B C$ in women receiving chemotherapy and HER2 targeted therapy the difference was less marked (pCR rate of $53 \%$ for IHC $3+$ versus $38 \%$ for IHC $2+$ /gene amplified, respectively). This again highlights the importance of making therapy decisions using both HER2 and ER status.

This study has some limitations. The number of cases in Group 2 was limited. The number of cases in Group 3 was also low $(n=9)$ limiting reliable statistical analysis for this group. This has been a limitation in other large studies, such as that of Press et al. ${ }^{20}$ in which only one BC was classified as Group 3 with an IHC score of $2+$. The number of cases with $\mathrm{IHC} 2+$ and high-level gene amplification was also limited, as might be expected. This may explain the low pCR rate observed in Group 1 in this study. However, the overall response rate of IHC $2+$ amplified BC in our study was in line with others ${ }^{27}$ using either the updated guidelines $^{3}$ (Groups $1+3$ ) or the 2013 ASCO/CAP recommendations. ${ }^{44}$ In order to report on sufficient cases with these uncommon patterns of HER2 expression, the cancers in this series were collected from several centres. Although there are some potential differences in disease stage and therapeutic regimens adopted between centres, this reflects real world data and is, we believe, therefore clinically relevant. Ideally, the data should be collected as part of a prospective randomised trial. More significantly, perhaps, no survival outcome measures could be included in this multi-institutional retrospective study as patients were treated in recent years without sufficient follow-up time; we hope that this information will be collected prospectively.

In conclusion, the rate of $\mathrm{pCR}$ to NACT and HER2 targeted treatment of $B C$ that is HER2 IHC $3+$ is higher than for tumours that are IHC $2+$ and HER2 amplified. The rates of $\mathrm{pCR}$ were similar in the ASCO/CAP Group 1 and Group 2 tumours showing score $2+$ HER2 protein expression. Although our data does not clearly refute the ASCO/CAP recommendation to exclude Group 2 from HER2 targeted therapy, it provides evidence that Group 2 with IHC score $2+$ should be evaluated further with respect to eligibility for HER2 targeted therapy. Further investigation, including prospective randomised clinical trials of this group is warranted.

\section{ACKNOWLEDGEMENTS}

We acknowledge all those who contributed to the collection of cases. We thank Nottingham Health Science Biobank and PathLAKE project for supporting this study. CaM is supported by AIRC under IG 2019-ID 22850 project. A.M.S. is supported by Birmingham Cancer Research UK Centre (C17422/A25154).

\section{AUTHOR CONTRIBUTIONS}

Conception and design: E.R., C.Q., E.P., A.S., Ca.M., G.G., R.M., C.P., D.P., S.P., I.O.E. and A.L. Cohort identification, Collection and assembly of data: I.M.M., C.Q., E.P., A.S., Ca.M., M.T., G.G., C.M., J.W., K.A., K.E., N.B., B.T., R.M., C.P., D.P., and S.P. Data analysis and interpretation: E.R., I.M.M., C.Q., E.P., A.S., Ca.M., M.T., G.G., C.M., J.W., K.A., K.E., N.B., B.T., R.M., C.P., D.P., S.P., I.O.E., and A.L. Manuscript writing: E.R., I.M.M., C.Q., E.P., A.S., Ca.M., M.T., G.G., C.M., J.W., K.A., K.E., N.B., B.T., R.M., C.P., D.P., S.P., I.O.E., and A.L. All authors contributed to revising and approving the final version of the manuscript. All authors declared their contribution(s) to the study.

\section{ADDITIONAL INFORMATION}

Ethics approval and consent to participate This study was approved by the Nottingham Research Tissue Bank Access Committee under the IRAS Project ID: 184265. All patients included were consented to participate in research. All samples were fully anonymised. The study was performed in accordance with the Declaration of Helsinki.

\section{Consent to publish Not applicable.}

Data availability The authors confirm the data that has been used is available on reasonable request.

Competing interests The authors declare no competing interests.

Funding information Not applicable.

Supplementary information The online version contains supplementary material available at https://doi.org/10.1038/s41416-021-01351-8.

Publisher's note Springer Nature remains neutral with regard to jurisdictional claims in published maps and institutional affiliations. 


\section{REFERENCES}

1. Ratcliffe, N., Wells, W., Wheeler, K. \& Memoli, V. The combination of in situ hybridization and immunohistochemical analysis: an evaluation of Her2/neu expression in paraffin-embedded breast carcinomas and adjacent normalappearing breast epithelium. Mod. Pathol. 10, 1247-1252 (1997).

2. Baselga, J., Norton, L., Albanell, J., Kim, Y. M. \& Mendelsohn, J. Recombinant humanized anti-HER2 antibody (Herceptin) enhances the antitumor activity of paclitaxel and doxorubicin against HER2/neu overexpressing human breast cancer xenografts. Cancer Res. 58, 2825-2831 (1998).

3. Wolff, A. C., Hammond, M. E. H., Allison, K. H., Harvey, B. E., Mangu, P. B., Bartlett, J. M. S. et al. Human epidermal growth factor receptor 2 Testing in breast cancer: American Society of Clinical Oncology/College of American Pathologists Clinical Practice Guideline Focused Update. J. Clin. Oncol. 36, 2105-2122 (2018).

4. Wolff, A. C., Hammond, M. E., Hicks, D. G., Dowsett, M., McShane, L. M., Allison, K. $\mathrm{H}$. et al. Recommendations for human epidermal growth factor receptor 2 testing in breast cancer: American Society of Clinical Oncology/College of American Pathologists clinical practice guideline update. J. Clin. Oncol. 31, 3997-4013 (2013).

5. Yamauchi, H., Stearns, V. \& Hayes, D. F. When is a tumor marker ready for prime time? A case study of c-erbB-2 as a predictive factor in breast cancer. J. Clin. Oncol. 19, 2334-2356 (2001).

6. Slamon, D. J., Leyland-Jones, B., Shak, S., Fuchs, H., Paton, V., Bajamonde, A. et al. Use of chemotherapy plus a monoclonal antibody against HER2 for metastatic breast cancer that overexpresses HER2. N. Engl. J. Med. 344, 783-792 (2001).

7. Vogel, C. L., Cobleigh, M. A., Tripathy, D., Gutheil, J. C., Harris, L. N., Fehrenbacher L. et al. Efficacy and safety of trastuzumab as a single agent in first-line treatment of HER2-overexpressing metastatic breast cancer. J. Clin. Oncol. 20, 719-726 (2002).

8. Untch, M., von Minckwitz, G., Gerber, B., Schem, C., Rezai, M., Fasching, P. A. et al. Survival analysis after neoadjuvant chemotherapy with trastuzumab or lapatinib in patients with human epidermal growth factor receptor 2-positive breast cancer in the GeparQuinto (G5) Study (GBG 44). J. Clin. Oncol. 36, 1308-1316 (2018).

9. Johnston, S. R. D., Hegg, R., Im, S. A., Park, I. H., Burdaeva, O., Kurteva, G. et al. Phase III, randomized study of dual human epidermal growth Factor receptor 2 (HER2) blockade with lapatinib plus trastuzumab in combination with an aromatase inhibitor in postmenopausal women with HER2-positive, hormone receptor-positive metastatic breast cancer: alternative. J. Clin. Oncol. 36, 741-748 (2018).

10. Wolff, A. C., Hammond, M. E., Schwartz, J. N., Hagerty, K. L., Allred, D. C., Cote, R. J. et al. American Society of Clinical Oncology/College of American Pathologists guideline recommendations for human epidermal growth factor receptor 2 testing in breast cancer. J. Clin. Oncol. 25, 118-145 (2007).

11. Cobleigh, M. A., Vogel, C. L., Tripathy, D., Robert, N. J., Scholl, S., Fehrenbacher, L. et al. Multinational study of the efficacy and safety of humanized anti-HER2 monoclonal antibody in women who have HER2-overexpressing metastatic breast cancer that has progressed after chemotherapy for metastatic disease. J. Clin. Oncol. 17, 2639-2648 (1999).

12. Sawaki, M., Ito, Y., Tada, K., Mizunuma, N., Takahashi, S., Horikoshi, N. et al. Efficacy and safety of trastuzumab as a single agent in heavily pretreated patients with HER-2/neu-overexpressing metastatic breast cancer. Tumori 90, 40-43 (2004).

13. Romond, E. H., Perez, E. A., Bryant, J., Suman, V. J., Geyer, C. E. Jr., Davidson, N. E. et al. Trastuzumab plus adjuvant chemotherapy for operable HER2-positive breast cancer. N. Engl. J. Med. 353, 1673-1684 (2005).

14. Kaufman, B., Mackey, J. R., Clemens, M. R., Bapsy, P. P., Vaid, A., Wardley, A. et al. Trastuzumab plus anastrozole versus anastrozole alone for the treatment of postmenopausal women with human epidermal growth factor receptor 2-positive, hormone receptor-positive metastatic breast cancer: results from the randomized phase III TAnDEM study. J. Clin. Oncol. 27, 5529-5537 (2009).

15. Joensuu, H., Kellokumpu-Lehtinen, P. L., Bono, P., Alanko, T., Kataja, V., Asola, R et al. Adjuvant docetaxel or vinorelbine with or without trastuzumab for breast cancer. N. Engl. J. Med. 354, 809-820 (2006).

16. Piccart-Gebhart, M. J., Procter, M., Leyland-Jones, B., Goldhirsch, A., Untch, M., Smith, I. et al. Trastuzumab after adjuvant chemotherapy in HER2-positive breast cancer. N. Engl. J. Med. 353, 1659-1672 (2005).

17. Ellis, I. O., Bartlett, J., Dowsett, M., Humphreys, S., Jasani, B., Miller, K. et al. Best Practice No 176: Updated recommendations for HER2 testing in the UK. J. Clin. Pathol. 57, 233-237 (2004).

18. Ellis, I. O., Dowsett, M., Bartlett, J., Walker, R., Cooke, T., Gullick, W. et al. Recommendations for HER2 testing in the UK. J. Clin. Pathol. 53, 890-892 (2000).

19. Rakha, E. A., Pinder, S. E., Bartlett, J. M., Ibrahim, M., Starczynski, J., Carder, P. J. et al. Updated UK recommendations for HER2 assessment in breast cancer. J. Clin. Pathol. 68, 93-99 (2015).

20. Press, M. F., Sauter, G., Buyse, M., Fourmanoir, H., Quinaux, E., Tsao-Wei, D. D. et al HER2 gene amplification testing by fluorescent in situ hybridization (FISH): comparison of the ASCO-College of American Pathologists Guidelines with FISH scores used for enrollment in breast cancer international research group clinical trials. J. Clin. Oncol. 34, 3518-3528 (2016).

21. Ballard, M., Jalikis, F., Krings, G., Schmidt, R. A., Chen, Y.-Y., Rendi, M. H. et al. 'Nonclassical' HER2 FISH results in breast cancer: a multi-institutional study. Mod. Pathol. 30, 227-235 (2017).

22. Dodson, A., Parry, S., Ibrahim, M., Bartlett, J. M., Pinder, S., Dowsett, M. et al. Breast cancer biomarkers in clinical testing: analysis of a UK national external quality assessment scheme for immunocytochemistry and in situ hybridisation database containing results from 199300 patients. J. Pathol. Clin. Res. 4, 262-273 (2018).

23. Cortazar, P., Zhang, L., Untch, M., Mehta, K., Costantino, J. P., Wolmark, N. et al. Pathological complete response and long-term clinical benefit in breast cancer: the CTNeoBC pooled analysis. Lancet 384, 164-172 (2014).

24. Hammond, M. E., Hayes, D. F., Dowsett, M., Allred, D. C., Hagerty, K. L., Badve, S et al. American Society of Clinical Oncology/College of American Pathologists guideline recommendations for immunohistochemical testing of estrogen and progesterone receptors in breast cancer. Arch. Pathol. Lab Med. 134, 907-922 (2010).

25. Owens, M. A., Horten, B. C. \& Da Silva, M. M. HER2 amplification ratios by fluorescence in situ hybridization and correlation with immunohistochemistry in a cohort of 6556 breast cancer tissues. Clin. Breast Cancer 5, 63-69 (2004).

26. Yaziji, H., Goldstein, L. C., Barry, T. S., Werling, R., Hwang, H., Ellis, G. K. et al. HER-2 testing in breast cancer using parallel tissue-based methods. JAMA 291 1972-1977 (2004).

27. Krystel-Whittemore, M., Xu, J., Brogi, E., Ventura, K., Patil, S., Ross, D. S. et al. Pathologic complete response rate according to HER2 detection methods in HER2-positive breast cancer treated with neoadjuvant systemic therapy. Breast Cancer Res. Treat. 177, 61-66 (2019).

28. Meisel, J. L., Zhao, J., Suo, A., Zhang, C., Wei, Z., Taylor, C. et al. Clinicopathologic factors associated with response to neoadjuvant anti-HER2-directed chemotherapy in HER2-positive breast cancer. Clin. Breast Cancer 20, 19-24 (2020).

29. Perez, E. A., Baehner, F. L., Butler, S. M., Thompson, E. A., Dueck, A. C., Jamshidian, F. et al. The relationship between quantitative human epidermal growth factor receptor 2 gene expression by the 21-gene reverse transcriptase polymerase chain reaction assay and adjuvant trastuzumab benefit in Alliance N9831. Breast Cancer Res. 17, 133 (2015).

30. Li, A. C., Zhao, J., Zhao, C., Ma, Z., Hartage, R., Zhang, Y. et al. Quantitative digital imaging analysis of HER2 immunohistochemistry predicts the response to antiHER2 neoadjuvant chemotherapy in HER2-positive breast carcinoma. Breast Cancer Res. Treat. 180, 321-329 (2020).

31. Veeraraghavan, J., De Angelis, C., Mao, R., Wang, T., Herrera, S., Pavlick, A. C. et al. A combinatorial biomarker predicts pathologic complete response to neoadjuvant lapatinib and trastuzumab without chemotherapy in patients with HER2+ breast cancer. Ann. Oncol. 30, 927-933 (2019).

32. Dowsett, M., Procter, M., McCaskill-Stevens, W., de Azambuja, E., Dafni, U., Rueschoff, J. et al. Disease-free survival according to degree of HER2 amplification for patients treated with adjuvant chemotherapy with or without 1 year of trastuzumab: the HERA Trial. J. Clin. Oncol. 27, 2962-2969 (2009).

33. Prat, A., Bianchini, G., Thomas, M., Belousov, A., Cheang, M. C., Koehler, A. et al. Research-based PAM50 subtype predictor identifies higher responses and improved survival outcomes in HER2-positive breast cancer in the NOAH study. Clin. Cancer Res. 20, 511-521 (2014).

34. Wuerstlein, R. \& Harbeck, N. Neoadjuvant therapy for HER2-positive breast cancer Rev. Recent Clin. Trials 12, 81-92 (2017).

35. Gianni, L., Pienkowski, T., Im, Y. H., Roman, L., Tseng, L. M., Liu, M. C. et al. Efficacy and safety of neoadjuvant pertuzumab and trastuzumab in women with locally advanced, inflammatory, or early HER2-positive breast cancer (NeoSphere): a randomised multicentre, open-label, phase 2 trial. Lancet Oncol. 13, 25-32 (2012).

36. Sanchez-Rovira, P., Segui, M. A., Llombart, A., Aranda, E., Anton, A., Sanchez, A et al. Bevacizumab plus preoperative chemotherapy in operable HER2 negative breast cancer: biomarkers and pathologic response. Clin. Transl. Oncol. 15, 810-817 (2013).

37. Li, A., Bai, Q., Kong, H., Zhou, S., Lv, H., Zhong, S. et al. Impact of the updated 2018 American Society of Clinical Oncology/College of American Pathologists Guideline for human epidermal growth factor receptor 2 testing in breast cancer. Arch. Pathol. Lab. Med. 144, 1097-1107 (2020).

38. Zhang, H., Moisini, I., Ajabnoor, R. M., Turner, B. M. \& Hicks, D. G. Applying the New Guidelines of HER2 Testing in Breast Cancer. Curr. Oncol. Rep. 22, 51 (2020).

39. Ahn, S., Woo, J. W., Lee, K. \& Park, S. Y. HER2 status in breast cancer: changes in guidelines and complicating factors for interpretation. J. Pathol. Transl. Med 54, 34-44 (2020).

40. Wang, X., Teng, X., Ding, W., Sun, K. \& Wang, B. A clinicopathological study of 30 breast cancer cases with a HER2/CEP17 ratio of $>/=2.0$ but an average HER 2 copy number of $<4.0$ signals per cell. Mod. Pathol. 33, 1557-1562 (2020). 
41. Montemurro, F., Di Cosimo, S. \& Arpino, G. Human epidermal growth factor receptor 2 (HER2)-positive and hormone receptor-positive breast cancer: new insights into molecular interactions and clinical implications. Ann. Oncol. 24, 2715-2724 (2013).

42. Prat, A., Carey, L. A., Adamo, B., Vidal, M., Tabernero, J., Cortés, J. et al. Molecular features and survival outcomes of the intrinsic subtypes within HER2-positive breast cancer. J. Natl Cancer. Inst. 106, dju152 (2014).

43. Loi, S., Dafni, U., Karlis, D., Polydoropoulou, V., Young, B. M., Willis, S. et al. Effects of estrogen receptor and human epidermal growth factor receptor-2 levels on the efficacy of trastuzumab: a secondary analysis of the HERA trial. JAMA Oncol. 2, 1040-1047 (2016)

44. Zhang, W., Tian, H. \& Yang, S. H. The efficacy of neoadjuvant chemotherapy for HER-2-positive locally advanced breast cancer and survival. Anal. Cell pathol. 2017, 1350618 (2017).
Open Access This article is licensed under a Creative Commons Attribution 4.0 International License, which permits use, sharing, adaptation, distribution and reproduction in any medium or format, as long as you give appropriate credit to the original author(s) and the source, provide a link to the Creative Commons license, and indicate if changes were made. The images or other third party material in this article are included in the article's Creative Commons license, unless indicated otherwise in a credit line to the material. If material is not included in the article's Creative Commons license and your intended use is not permitted by statutory regulation or exceeds the permitted use, you will need to obtain permission directly from the copyright holder. To view a copy of this license, visit http://creativecommons. org/licenses/by/4.0/.

(c) The Author(s) 2021 